\title{
Prevalence and Factors Associated with Current Smoking Among Medical Students in Coastal South India
}

\author{
Ganesh Kumar $\mathrm{S},{ }^{1}$ Subba $\mathrm{SH},{ }^{2}$ Unnikrishnan $\mathrm{B},{ }^{2}$ Jain $\mathrm{A},{ }^{2}$ Badiger $\mathrm{S}^{3}$
}

\author{
${ }^{1}$ Department of Preventive and Social Medicine \\ Jawaharlal Institute of Postgraduate Medical \\ Education and Research (JIPMER) \\ Puducherry, India \\ ${ }^{2}$ Department of Community Medicine \\ Kasturba Medical College \\ Manipal University \\ Mangalore, India \\ ${ }^{3}$ KSHEMA, Mangalore, Karnataka
}

\section{Corresponding Author}

Ganesh Kumar S

Department of Preventive and Social Medicine

JIPMER

Puducherry -06, India

Email: sssgan@yahoo.com

Citation

Ganesh Kumar S, Subba SH, Unnikrishnan B, Jain A, Badiger S. Prevalence and Factors Associated with Current Smoking Among Medical Students in Coastal South India Kathmandu Univ Med J 2011;36(4):233-7.

\section{ABSTRACT}

\section{Background}

Smoking among health care personnel such as medical students is an important public health issue. More effective measures to reduce tobacco smoking among medical students are needed worldwide. Very few studies had been conducted in past in India and other developing countries to understand the magnitude of problem.

\section{Objectives}

To determine the prevalence and associated factors of current smoking among medical students.

\begin{abstract}
Methods
Cross sectional study was conducted during January and February 2009 among 333 study subjects selected randomly from four batches of a teaching institution. Subjects were administered a self administered pre tested questionnaire and smoking status was assessed as per the criteria laid down by WHO. Proportion, chi square test and multiple logistic regression analysis were used for statistical analysis.
\end{abstract}

\section{Results}

The prevalence of current smoking was found to be $22.4 \%$ (67). There were widespread deficiencies in knowledge of smoking among students of different classes, as an important causal factor in many diseases like gastro intestinal malignancy, heart problems, asthma, and emphysema. It was found that only half of them were willing to quit smoking (33). Fourth year students $(O R=2.54)$ and presence of peer pressure $(O R=21.91)$ had independent significant association with current smoking.

\section{Conclusion}

Prevalence of smoking among medical students is high that warrants adoption of comprehensive smoking control interventions among them.

\section{KEYWORDS}

Knowledge, Peer pressure, Prevalence, Smoking,

\section{INTRODUCTION}

Smoking among health care personnel such as medical students is an important public health issue. More effective measures to reduce tobacco smoking among medical students are needed worldwide. ${ }^{1}$ A recent study in Kerala showed that substantial proportion of physicians and medical students continue to smoke. ${ }^{2}$ Certain factors that commonly play a role in initiation of tobacco use include exposure to tobacco marketing efforts, role modeling by parents or other adults, peer pressure, collateral addiction to other drugs and inadequate knowledge about injurious effects of tobacco use.

It is the public health priority to educate medical students for behavior modification generally in the age group
17-25 years, when lifestyle patterns both healthy and unhealthy, are formed. Before initiating such interventions, it is important to understand the magnitude, the factors contributing and awareness with regard to smoking habits among medical students. Very few studies had been conducted in past in India and other developing countries to understand the magnitude of problem. ${ }^{3-6}$ Studies of such nature will be a useful tool for developing interventional programmes for the smokers. Therefore this study was undertaken with the objective of estimating the prevalence and to identify the factors associated with smoking among medical students of a medical college in Mangalore city of coastal Karnataka, India. 


\section{METHODS}

A cross-sectional study was done among the male medical undergraduate students of Kasturba Medical College, Mangalore, a coastal city in Karnataka, South India. Out of the five medical colleges in Mangalore, above medical college was selected considering the feasibility constraints. The study was carried out from January to February 2009. The total number of students in all four batches was 1000. Each batch has two classes therefore there are total of eight classes. Sample size was estimated by using the formula $4 \mathrm{pq} / \mathrm{d}^{2}$, where prevalence was taken as $25 \%$ and precision as $20 \% .^{5}$ Using the above formula sample size was estimated to be 300 . After adding non response rate of $10 \%$, an additional 33 subjects were included. Thus 333 subjects were selected for the study.

Probability proportional to sampling technique was used to select the study sample from each class. In each of the four classes, using the students register, the subjects were selected randomly from the random number table and the names of the subjects from that year register were noted down. Similarly, the names of the subjects of the next class from the register were noted down. Participation in the study was voluntary and verbal informed consent was taken from the participating students. Out of the total 333 students, only 299 students had responded for final analysis.

The participants were administered a self administered pre tested questionnaire and smoking status was assessed as per the criteria laid down by WHO.7 "Current use" was defined as "having smoked at least once in the last 30 days preceding the survey'. "Never use" was defined as 'having not smoked even once in their lifetime'. Students were briefed about the purpose of the study and requested to fill the questionnaire. Students were not required to write their names to ensure confidentiality and to elicit correct responses from them. The information was collected from the students regarding age, class of studying, age at initiation, factors for the initiation like peer pressure, pan chewing habit and paternal history of smoking. Other information that includes frequency, money spent per week, number of cigarettes and willingness to quit smoking were collected. Awareness of the students to smoking related issues were also collected.

The data collected was tabulated, coded and analyzed using Microsoft Excel and Statistical Package for Social Sciences (SPSS) version 11.5 for windows. Chi-square test was carried out to test the significance of difference between two proportions. For all the tests, $p$ value $<0.05$ was considered significant. To determine the independent effect of various factors on smoking, multiple logistic regression analysis was performed.
Table 1. Prevalence of current smoking according to various factors.

\begin{tabular}{|c|c|c|c|}
\hline Variables & $\begin{array}{l}\text { Number of } \\
\text { subjects }\end{array}$ & Prevalence (\%) & $\chi^{2}, p$ value \\
\hline \multicolumn{4}{|l|}{ Age } \\
\hline $18-19$ & 81 & 9 (11.1) & \multirow{5}{*}{$11.26,0.01$} \\
\hline $20-21$ & 102 & $23(22.5)$ & \\
\hline $22-23$ & 69 & $19(27.5)$ & \\
\hline $24-25$ & 47 & $16(34.0)$ & \\
\hline \multicolumn{3}{|c|}{ Year of studying } & \\
\hline First & 91 & $11(12.1)$ & \multirow{4}{*}{$15.25,0.004$} \\
\hline Second & 75 & $15(20.0)$ & \\
\hline Third & 53 & $16(30.2)$ & \\
\hline Fourth & 80 & $25(31.3)$ & \\
\hline \multicolumn{4}{|c|}{ Peer pressure } \\
\hline Present & 35 & $28(80.0)$ & \multirow{2}{*}{$75.62,<0.001$} \\
\hline Absent & 264 & $39(14.8)$ & \\
\hline \multicolumn{4}{|c|}{ Parental history } \\
\hline Present & 83 & $27(32.5)$ & \multirow{2}{*}{$6.77,0.009$} \\
\hline Absent & 216 & $40(18.5)$ & \\
\hline \multicolumn{4}{|c|}{ Pan chewing } \\
\hline Yes & 28 & 12 (42.9) & \multirow{2}{*}{$7.43,0.006$} \\
\hline No & 271 & $55(20.3)$ & \\
\hline
\end{tabular}

Table 2. Prevalance of current smoking: Multiple Logistic Regression Analysis

\begin{tabular}{|lll|}
\hline Variables & $\begin{array}{l}\text { Odds ratio adjusted } \\
(95 \% \mathrm{Cl})\end{array}$ & P value \\
\hline Year studying & & \\
\hline First & - & - \\
\hline Second & $1.03(0.39-2.78)$ & 0.95 \\
\hline Third & $2.19(0.83-5.78)$ & 0.11 \\
\hline Fourth & $2.54(1.07-6.02)$ & 0.04 \\
\hline Peer pressure & & \\
\hline Absent & - & - \\
\hline Present & $21.91(8.55-56.16)$ & $<0.001$ \\
\hline Parental History & & \\
\hline Present & - & - \\
\hline Absent & $1.78(0.90-3.50)$ & 0.10 \\
\hline Pan chewing & & - \\
\hline Yes & - & 0.09 \\
\hline No & $2.33(0.87-6.19)$ & \\
\hline
\end{tabular}




\section{RESULTS}

Of the 333 subjects enrolled into the study, 299 subjects were available for final analysis (response rate $89.8 \%$ ). The mean age of our study subjects was 21.1 years (19.05, 23.15). One third of the subjects belonged to $20-21$ years age group $(102,34.1 \%)$ followed by $18-19$ years age group (81, 27.1\%). 92 (30.77\%) subjects were first year and 80 (26.76\%) were final year students.

The results in the present study revealed that, out of total students ( $n=299), 67(22.4 \%)$ were found to be current smokers. The prevalence of current smoking among 24-25 years age group was $34 \%$. As the age advanced, prevalence increased significantly $\left(\chi^{2}=11.26, p=0.04\right)$. Similarly the prevalence was high among 4th year medical students $(31.3 \%)$ and was found to be significant $\left(\chi^{2}=15.25, p=0.004\right)$. Among those with peer pressure, the prevalence was five times more compared to those without peer pressure group $\left(\chi^{2}=75.62, p=<0.001\right)$ (Table 1$)$. Multiple logistic regression analysis revealed that fourth year students $(O R=2.54)$ and presence of peer pressure $(O R=21.91)$ had independent significant association with current smoking (Table 2). Nearly one third (32.5\%) of those with parental history of smoking were current smokers and those without parental history had a prevalence rate of $18.5 \%$. The familial aggregation of the current smoking was quite evident in the present study, with smoking being more common among students belonging to families where smoking is prevalent $\left(\chi^{2}=6.77, p=0.009\right)$. The present study showed that $17.9 \%(12)$ of the current smokers were pan chewers $\left(\chi^{2}=7.43, p=0.006\right)$. The prevalence of pan chewing was $9.4 \%$ (28) among the male medical students (Table-1)

Around $66.66 \%(45)$ of the current smokers were smoking daily and started smoking (42) during 16-20 years age. Around $75 \%$ (74.6\%) started smoking after the age of sixteen years. Majority were smoking less than five cigarettes (59.7\%) and around $28.4 \%$ were smoking 6-10 cigarettes per day. One third (34.3\%) of the current smokers were spending 100-200 rupees per week for smoking. Half $(50.7 \%)$ of the smokers were still not willing to quit smoking habit. Those who were willing, ill effects were the most common reason $(67 \%, 22)$ to quit smoking (Table 3$)$.
Around $11 \%$ (33) of them were unaware of the public ban on smoking. Among those who aware, majority felt that it had no effect on them $(84 \%, 223) .13 .7 \%$ (42) of students do not support public ban on smoking. $3 / 4(224)$ of the students agreed that smoking should be banned, while 19\% (57) of them felt that advertisements should be banned. Around one third of them were unaware regarding injurious effects of the smoking like heart attack, asthma and emphysema. Nearly half $(42.8 \%)$ of them were still unaware on its effect of gastro intestinal malignancy. The difference in awareness regarding the injurious effects of smoking among different classes was found to be significant (Table 4).

Table 3. Distribution of current smokers according to smoking related factors. $n=67$

\begin{tabular}{|ll|}
\hline Factors & Numbers \\
\hline Frequency & \\
\hline Everyday & $45(67.2)$ \\
\hline Few days in a week & $17(25.4)$ \\
\hline Few times in a month & $5(7.5)$ \\
\hline Age of starting (years) & \\
\hline$<10$ & $5(7.5)$ \\
\hline $11-15$ & $12(17.9)$ \\
\hline $16-20$ & $42(62.7)$ \\
\hline $21-25$ & $8(11.9)$ \\
\hline Number of cigarettes & \\
\hline $1-5$ & $40(59.7)$ \\
\hline $6-10$ & $19(28.4)$ \\
\hline $11-15$ & $7(10.4)$ \\
\hline $16-20$ & $1(1.5)$ \\
\hline Money spent per week & $5(7.5)$ \\
\hline$<100$ & $27(40.3)$ \\
\hline $100-200$ & $23(34.3)$ \\
\hline $201-300$ & $12(17.9)$ \\
\hline$>300$ & \\
\hline
\end{tabular}

Table 4. Awareness on smoking related issues among medical students.

\begin{tabular}{|c|c|c|c|c|c|c|}
\hline Awareness & $\begin{array}{l}1^{\text {st }} \text { year students } n \\
=91(\%)\end{array}$ & $\begin{array}{l}2^{\text {nd }} \text { year students } \\
n=75(\%)\end{array}$ & $\begin{array}{l}3^{\text {rd }} \text { year students } \\
n=53(\%)\end{array}$ & $\begin{array}{l}4^{\text {th }} \text { year students } \\
n=80(\%)\end{array}$ & Total n = $299(\%)$ & $\chi 2, p$ value \\
\hline Ban on public smoking & 80 (87.9) & $66(88.0)$ & 45 (84.9) & $75(93.8)$ & $266(89.0)$ & $2.93,0.403$ \\
\hline Addiction potential & $72(79.1)$ & $58(77.3)$ & $41(77.4)$ & $72(90.0)$ & $243(81.3)$ & $5.58,0.134$ \\
\hline Heart problems & $52(57.8)$ & $51(68.0)$ & $40(75.5)$ & $67(83.8)$ & $210(70.2)$ & $15.3,0.002$ \\
\hline Lung cancer & $78(85.7)$ & $62(82.7)$ & $49(92.5)$ & $79(98.8)$ & $268(89.6)$ & $13.0,0.005$ \\
\hline Asthma & $51(56.0)$ & $49(65.3)$ & $41(77.4)$ & $68(85.0)$ & 209 (69.9) & $19.1,<0.001$ \\
\hline Emphysema & $33(36.3)$ & $65(86.7)$ & $46(86.8)$ & $72(90.0)$ & $216(72.2)$ & $84.7,<0.001$ \\
\hline Gasrointestinal malignancy & $18(19.8)$ & $31(41.3)$ & $45(84.9)$ & $77(96.3)$ & $171(57.2)$ & $126.0,<0.001$ \\
\hline Dental staining & $38(41.8)$ & $69(92.0)$ & $48(90.6)$ & $74(92.5)$ & $229(76.6)$ & $88.6,<0.001$ \\
\hline
\end{tabular}




\section{DISCUSSION}

In the present study, an overall prevalence rate of current smoking among male medical students was found to be $22.4 \%$, signifying that substantial proportion of them smoked.

The results of other studies among academic medical students showed that the prevalence of tobacco smoking was comparable to our findings. ${ }^{5,8,9}$ Some studies done in India and abroad have shown low prevalence rates ranging from $3 \%$ to $14.2 \% .^{2,6,10,11}$ But some other studies have shown very high prevalence rate among male medical students. ${ }^{3,12-15}$ One school based study among 13-18 years age group showed prevalence as little as $1.5 \% .{ }^{16}$ Another study done in Karachi among adolescents found the prevalence as $13.7 \% .{ }^{17}$ In contrast to this, another study at East Timor Leste found the prevalence among male adolescents as 59\%. ${ }^{18}$ Recent community based study done in the neighboring district showed the prevalence as little as 4.5\% among 20-29 years age group. ${ }^{19}$ Another study done at Mangalore among Arts male students among 17-24 years age group found the prevalence as $33.1 \% .^{20}$ The widely differing prevalence rate of smoking found in these studies could be due to wide differences in the samples and definitions used, geographical area involved and importantly social factors like parental smoking, peer pressure and other habits like alcohol consumption. Besides medical students here come from different parts of the country which may be responsible for this varied prevalence rate.

The prevalence of current smoking among third and fourth year medical students was higher in comparison to first year students. The rate of smokers among the first-year medical students is also higher than in general population. ${ }^{19}$ However around half of smokers want to give up their habit. As the curriculum year progressed, the prevalence increased significantly. Our study is consistent

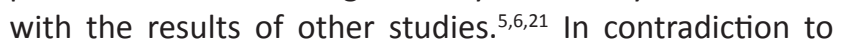
this, one study showed that prevalence is more among first year medical students. ${ }^{11}$ The increasing prevalence of smoking among third and fourth year medical students may be because of comparatively more peer pressure among these medical students. Peer pressure is shown as an important risk factor for initiation of smoking. ${ }^{5,6,11}$ The association between having a close friend who smoked and adolescent's own smoking may suggest that an adolescent who is a smoker may be more likely to choose other smokers as friends. Alternatively, having a friend who smokes may be an influence in initiating smoking. Subjects who have parents who smoke may also have higher acceptability of smoking as shown in our study.

There were widespread deficiencies in knowledge of smoking as an important causal factor in many diseases like gastro intestinal malignancy, heart problems, asthma, emphysema among first and also second year medical students. One study highlighted that awareness of medical students for the effect of smoking on coronary artery disease was very poor (13\%). ${ }^{22}$ It was shown that only half of them were willing to quit smoking which is alarming. International studies highlighted that majority of medical students start smoking during their undergraduate years. $^{21,22}$ So this is an appropriate time to raise the consciousness of the future doctors given that it is easier to prevent it at primary level.

Like in all surveys that rely on self-reported data, there is always a possibility of both inadvertent and deliberate misreporting. We do however believe that any bias which may have been introduced as a result of non availability of study participants was likely to be minimal as the response rate was high.

\section{CONCLUSION}

Smoking among male medical students is of great concern. Also, final year medical students and presence of peer pressure plays a major role as independent determinants of smoking. Their awareness is also poor with respect to some hazards of smoking. With the above context, it is necessary to bring positive behavioral changes through adoption of comprehensive smoking control interventions, counseling methods for quitting smoking and health education in medical universities.

\section{REFERENCES}

1. Smith DR, Leggat PA. An international review of tobacco smoking among medical students. J Postgrad Med 2007; 53: 55-62.

2. Mohan S, Pradeepkumar AS, Thresia CU, Thankappan KR, Poston WS, Haddock CK et al. Tobacco use among medical professionals in Kerala, India: the need for enhanced tobacco cessation and control efforts. Addictive Behaviors 2006 ;31: 2313-8.

3. Singh VV, Singh CZ, Banerjee A, Basannar DR. Determinants of Smoking Habit among Medical Students. MJAFI 2003; 59 : 209-11.

4. Venkataraman S, Mukhopadhya A, Muliyil J. Trends of smoking among medical students. Indian Journal of Medical Research 1996;104: 31620.

5. Ranjeeta Kumari, Bhola Nath. Study on the Use of Tobacco among Male Medical Students in Lucknow. Indian Journal of Community Medicine 2008; 33: 100-3.

6. Ramakrishna GS, Sankara Sarma P, Thankappan KR. Tobacco use among medical students in Orissa. The National medical Journal of India 2005; 18: 285-88.

7. World Health Organization. Guidelines for controlling and monitoring the tobacco epidemic. Geneva: World Health Organization; 1998:7680.

8. Veryga A, Stanikas T. Smoking habits, attitudes and smoking cessation among sixth-year medical students of Kaunas University of Medicine. Medicina (Kaunas) 2005;41: 607-13.

9. Sieminska A, Jassem JM, Uherek M, Wilanowski T, Nowak R, Jassem E. Tobacco smoking among the first-year medical students. Pneumonol Alergol Pol 2006;74:377-82.

10. Babalola Faserua, Noel C B, Patrick SH, Folashade O. Smoking behavior and perception of risk among medical students in Ibadan, Nigeria. Prev and control 2006; 2: 103-9. 
11. Nawaz H, Imam SZ, Zubairi AB, Pabaney AH, Sepah YJ, Islam M, Khan JA. Smoking habits and beliefs of future physicians of Pakistan. Int J Tuberc Lung Diseases 2007 ;11:915-9.

12. Vrazic $H$, Ljubicic $D$, Schneider NK. Tobacco use and cessation among medical students in Croatia--results of the Global Health Professionals Pilot Survey (GHPS) in Croatia, 2005. Int Journal of Public health 2008;53:111-7.

13. Vinnikov D, Lahdensuo A, Brimkulov N. Medical students of Kyrgyzstan: Smoking prevalence and attitudes to smoking cessation counseling. Prevention and Control 2006; 2: 31-37.

14. Mumtaz B, Chaudhary IA, Arshad M, Samiullah. Comparison of Smoking Behaviour Among Medical and other College Students in Rawalpindi. Journal of Coll physicians Surg Pak 2009;19:7-10.

15. Kanicka M, Szpak A, Drygas W, Rzeznicki A, Kowalska A. The prevalence of tobacco smoking among public health students at medical university of Bialystok. Advances in Medical Sciences 2007; 52:60-63.

16. Singh V, Gupta R. Prevalence of tobacco use and awareness of risks among school children in Jaipur. Journal of Assoc Physicians India 2006; 54: 609-12.
17. Shafquat Rozi1, Saeed Akhtar1, Sajid Ali1 and Javaid Khan. Prevalence and factors associated with current smoking among high school adolescents in Karachi, Pakistan. Southeast Asian Journal of Tropical Medicine Public Health 2005; 36: 498-504.

18. Siziya S, Muula AS, Rudatsikira E. Prevalence and correlates of current cigarette smoking among adolescents in East Timor- Leste. Indian Paediatrics 2008; 45: 963-68.

19. Anjali BD, Nagaraj K, Kamath R. Prevalence and determinants of tobacco use in a highly literate rural community in southern India. The National Medical Journal of India 2008; 21: 163-65.

20. Sajjan BS, Chacko J, Asha K. Smoking behaviour among arts student of a college in Mangalore, Dakshina Kannada. Indian Journal of Medical Sciences 2003;57:290-93.

21. Zhu T, Feng B, Wong S, Choi W, Zhu SH. A comparison of smoking behaviors among medical and other college students in China. Health Promotion International 2004; 19: 189-196.

22. Zhou L, Haung JH, Liu JZ. Smoking among shanghai medical students and the need for comprehensive intervention strategies. Health Promotion International 1997; 12: 27-32. 